\title{
CIDADES-SANTUÁRIO E O DIREITO À CIDADE: REPENSANDO PERTENCIMENTO A PARTIR DAS CIDADES
}

\author{
Sanctuary Cities and the Right to the City: \\ Rethinking belonging through cities
}

André Zuzarte*

\begin{abstract}
Resumo. Em tempos de criminalização da migração, o espaço urbano (re) produz uma miríade de estratégias e mecanismos de controle que nega aos imigrantes, enquanto não cidadãos, a possibilidade de pertencimento e participação nas cidades modernas. A partir do diálogo com os escritos de Henri Lefebvre sobre o direito à cidade, argumento, porém, que o urbano traz em si possibilidades de construção de formas alternativas de pertencimento que desafiam os processos de exclusão que lhes são impostos. Através do movimento de cidades-santuário, este artigo ilustra como as cidades abrigam processos que desafiam a criminalização da migração e os limites impostos pela definição tradicional de cidadania.
\end{abstract}

Palavras chave: cidades-santuário; cidadania; direito à cidade; imigração.

Abstract. In times of migration criminalization, urban space (re) produces a myriad of strategies and control mechanisms that deny immigrants, as non-citizens, the possibility of belonging and participation in modern cities. From the dialogue with Henri Lefebvre's writings on the right to the city, I argue, however, that the urban brings possibilities to construct alternative forms of belonging that challenge the processes of exclusion imposed on them. Through the sanctuary city movement, we illustrate how cities harbor processes that challenge the criminalization of migration and the limits imposed by the traditional definition of citizenship.

Keywords: sanctuary cities; citizenship; right to the city; immigration.

\footnotetext{
Vice coordenador do Centro de Proteção a Refugiados e Imigrantes (CEPRI/Fundação Casa de Rui Barbosa). Rio de Janeiro - RJ, Brasil. E-mail: zuzarte.andre@gmail.com. Orcid: 0000-00032837-7208.
} 


\section{Introdução}

Movimentos migratórios sempre fizeram parte da história das cidades. Seja em narrativas bíblicas, na antiguidade ou na Idade Moderna, abundam relatos acerca de estrangeiros que fincaram raízes no meio urbano em busca de liberdade, oportunidades ou proteção. Como no passado, as pessoas hoje continuam a migrar para as cidades ávidas em encontrar condições favoráveis para reconstruírem suas vidas. No entanto, a crescente criminalização da migração tem estabelecido uma realidade diferente.

Como diferentes trabalhados evidenciam, o urbano abriga uma miríade de estratégias e mecanismos de controle e regulação que nega aos imigrantes, enquanto não cidadãos, a possibilidade de pertencimento e participação nas cidades modernas (ver, por exemplo, Balibar, 1998; Ridgley, 2008; Nyers, 2010). Nesta leitura, o urbano surge como espaço de replicação e aprofundamento das políticas e práticas estatais de exclusão, evidenciando que a criminalização de imigrantes ocorre não apenas nas fronteiras nacionais, mas cada vez mais nas cidades - nos locais de trabalho, nas escolas e em situações nas quais as pessoas podem ser identificadas como não pertencentes à comunidade nacional (Bauder, 2016).

A partir do diálogo com a teoria urbana crítica, especialmente com escritos de Henri Lefebvre sobre o direito à cidade, argumento, porém, que o urbano traz em si possibilidades de construção de diferentes formas de pertencimento e participação que desafiam os processos de exclusão que lhes são impostos. De acordo com a concepção lefebvriana, o urbano é constituído pela tensão dialética entre a dominação, de um lado, e a apropriação do outro (Lefebvre, 1991, 1999, 2001). Em outras palavras, se o urbano tem sido historicamente um espaço de processos de exclusão e discriminação em nome da manutenção da ordem e controle social, tem também abrigado práticas que desafiam e contestam os regimes dominantes. Neste sentido, é necessário se atentar para as formas como os habitantes das cidades, independente de seu status jurídico, mobilizam conexões, estratégias e adaptações através das quais redefinem os limites da cidadania e reivindicam o direito de pertencer e participar da vida urbana.

Como Holston (2009) sintetiza, as cidades modernas são, assim, um espaço de colisão entre as forças de exploração e despossessão, por um lado, e, por outro, de práticas variadas que fazem emergir novas subjetividades políticas através das quais se reivindicam novas formas de pertencimento e justiça social. Deste conjunto de práticas, enfatizo as formas de contestação mais organizadas, representadas pelo movimento das cidades-santuário. Este estudo é um desdobramento de uma pesquisa mais ampla apresentada em 
minha tese de doutoramento acerca da relação entre a chamada crise do refúgio e a crise das cidades (Bravo, 2019).

Nas seções seguintes, faço um breve apanhado da literatura que explicita como os imigrantes, especialmente os não documentados ${ }^{1}$, que habitam as cidades são excluídos da plena participação na vida nacional, em maior escala, e da vida urbana, em menor escala. Na sequência, a partir da obra de Lefebvre e de outros atores que seguem a trajetória aberta por sua obra, como David Harvey (2014), buscarei mostrar como o urbano abriga processos que subvertem noções cristalizadas de cidadania e de quem tem o direito a ter direitos. Em seguida, lanço luz sobre o movimento de cidades-santuário ao redor do mundo e argumento que estes não representam apenas espaços de resistência, mas de materialização de formas alternativas de pertencimento que se pautam não pela posse de um status formal, mas pela presença no espaço urbano - aproximando-se da noção lefebvriana de direito à cidade.

\section{As cidades como zonas (re)produtoras de fronteiras}

O avanço da globalização que se seguiu ao fim da ordem bipolar alimentou o otimismo no surgimento de um mundo livre de fronteiras e divisões. Símbolo dessa utopia, a queda do muro de Berlim foi recebida com júbilo por alemães e milhões de outras pessoas que sonhavam com maior cooperação e abertura em um mundo mais globalista e liberal. No entanto, 30 anos depois, presenciamos a construção em escala inédita de novos muros entre e dentro dos Estados. Calcula-se que das 51 barreiras construídas ao longo das fronteiras desde o fim da Segunda Guerra-Mundial, aproximadamente metade surgiu entre os anos 2000 e 2014 (Ron Hassner, Jason Wittenberg, 2015; Ramo, 2016).

Os novos muros de Berlim são construídos sob o argumento de proteger os territórios nacionais da presença de contrabandistas, terroristas e, especialmente, imigrantes. Desde 2015, quando as atenções internacionais se voltaram para a chamada crise de refugiados, a construção de muros tornou-se uma promessa ainda mais frequente nos discursos de líderes políticos mundiais². A eles, se

\footnotetext{
Utilizo o termo indocumentado em detrimento de irregular ou ilegal tendo em vista que estes últimos configuram condições construídas e imputadas pelos Estados e que estão diretamente relacionadas aos processos de criminalização das migrações. Nesse sentido, enquanto uma pequena parcela de imigrantes é regularizada e tem acesso a (poucos) direitos dos nacionais, outra parcela, indesejada, é ilegalizada, tornando-se passível de punição e expulsão.

2 Em 2016, durante sua campanha presidencial, Donald Trump prometeu construir um muro na fronteira entre Estados Unidos e México com o objetivo de frear a entrada de imigrantes ilegais. Dois anos depois, em um esforço de angariar apoio à sua empreitada, discursou em rede nacional, enfatizando como todos os americanos tem sido "feridos pela imigração ilegal e descontrolada" que "drena recursos públicos e reduz empregos e salários" (Oval Office, 2019). Outras nações ao redor do mundo adotaram a mesma prática. Na Europa, desde 2015, foram construídos mais de 100 mil quilômetros de muros, em países como Áustria, Bulgária, Grécia e Hungria (Cierco, Silva, 2016; Stone, 2018).
} 
somam outros múltiplos aparatos de segurança anunciados como meios para resguardar a integridade dos territórios nacionais da presença incômoda e, principalmente, ameaçadora de corpos estrangeiros. Longe do declínio propagado pelos entusiastas da globalização, o Estado-nação reafirma sua autoridade através deste extenso aparato para policiamento de suas fronteiras ${ }^{3}$.

Como nos mostra Fassin (2011) e Nyers (2010), esse movimento tem se replicado em nível local, com a multiplicação de fronteiras físicas e simbólicas a permear o dia a dia de imigrantes. As cidades surgem, assim, como um espaço de fronteirização a traduzir as políticas e medidas de controle do Estado-nação para contextos urbanos específicos. Seus espaços são geridos pela compreensão convencional do direito a habitar e pertencer, atrelado ao reconhecimento formal, expresso, em última instância, pela posse da cidadania. Como consequência, replicam e desenvolvem práticas de controle, contenção e expulsão dos não cidadãos.

Segundo Ridgley (2008, p. 56), a criminalização da migração e a intensificação de estratégias de controle tem tornado as cidades "espaços nos quais as fronteiras racializadas da cidadania nacional são reforçadas e o significado do status formal de cidadania se torna palpável de formas muito diferentes". Margit (2017) identifica três campos de intervenção que considera os principais no que se refere às diferentes formas pelas quais se manifesta o controle migratório no ambiente urbano. Embora não forneçam um quadro integral, esses campos evidenciam a ampla variedade de instâncias regulatórias a que estão submetidos os não cidadãos. O primeiro deles retrata a ampla participação da polícia nos esforços locais de controle das fronteiras, traduzido na detenção de pessoas suspeitas de estarem no país sem autorização, na investigação do status migratório em diferentes espaços rotineiros, bem como na apreensão e deportação de imigrantes sem documentação ${ }^{4}$.

O segundo campo de intervenção diz respeito ao acesso a serviços sociais locais, que frequentemente envolvem questões de elegibilidade, já que a possibilidade de acesso é comumente determinada pela legislação nacional ou local - o que os torna parte do controle do status legal de uma pessoa. $\mathrm{Na}$ Alemanha, que possui uma dura lei nacional a restringir o acesso aos estrangeiros, verificou-se que os funcionários públicos em cidades como Berlim examinam minuciosamente os passaportes, vistos e permissões de residência

3 Para Brown (2010), os muros e cercas são uma das formas mais visíveis de demonstração de força de um Estado cujo poder está em xeque e que, por isso mesmo, necessita ostentar de modo o mais explícito possível uma potência que estaria perdendo - especialmente no que se refere à capacidade de controlar fluxos através de suas fronteiras.

4 Segundo Varsanyi (2008), essas medidas são majoritariamente aplicadas de forma seletiva pelas forças policiais locais, atingindo especialmente os grupos vistos como mais propensos a serem ilegais. No caso dos Estados Unidos, país estudado pela autora, se traduziu em interrogatórios e batidas frequentes nos locais frequentados por latinos. 
no acesso a serviços de educação e saúde, principalmente. O terceiro campo, por fim, corresponde à habitação, no qual as autoridades locais e os serviços sociais locais podem influenciar onde os imigrantes vivem através de políticas de assentamento que designam os espaços nos quais podem habitar ${ }^{5}$.

Todas essas estratégias de controle e exclusão dos imigrantes manifestas no espaço urbano comprovam que as cidades, mais do que meros repositórios das políticas migratórias nacionais, ensejam, elas mesmas, o surgimento de novas lógicas em nível de política (Magnusson, 2011; Isin, 2002, 2004). Usando as ferramentas a sua disposição, como portarias locais e decretos de uso da terra, um número crescente de municípios e estados vêm buscando restringir as oportunidades dos não cidadãos no espaço urbano - e, em última instância, provocar sua expulsão ${ }^{6}$. Neste sentido, como sintetiza Nyers (2010, p. 132)

(...) para pessoas sem status ${ }^{7}$, a fronteira não é apenas pontos de entrada físicos em portos, aeroportos e cruzamentos terrestres. Claramente, a política de fronteira não é mais limitada (se é que alguma vez foi) às linhas finas que separam o interno do estrangeiro, o aqui de lá, nós deles, o normal do excepcional (...). A fronteira é um local muito mais denso e mais complicado de práticas; não é "principalmente um lugar, mas um processo" (AAS, 2005) (...) A fronteira é, portanto, generalizada e aparentemente onipresente. Para pessoas sem status, a fronteira se tornou literalmente um "lugar onde se reside" (Balibar, 2002). Surgem em locais como clínicas de cuidados de saúde, cooperativas de habitação social, escolas, bancos de alimentos, gabinetes de assistência social, delegacias de polícia (...). Para pessoas sem status, as atividades cotidianas (trabalhar, dirigir e ir à escola) correm o risco de se transformar em atos criminosos e ilícitos com consequências terríveis.

Todos os pontos até aqui abordados evidenciam o papel central que as cidades têm desempenhado no reescalonamento do controle de fronteiras, estendendo a responsabilidade sobre o policiamento das fronteiras a novos domínios da vida cotidiana através, principalmente, da mobilização de uma ampla gama de autoridades, serviços e profissionais (Darling, 2016). Neste sentido, fica claro que as condições de vida dos imigrantes, especialmente

5 Para Boswell (2003) e Hynes (2009), as políticas de assentamento são concebidas e planejadas em função dos interesses estatais e não das necessidades e desejos daqueles a quem deveria atender. Desse modo, a busca por reduzir os encargos econômicos, políticos e sociais inerentes ao processo de alocação desses indivíduos resulta em sua transferência para áreas periféricas das cidades, carentes de serviços e facilidades para a reconstrução de suas vidas.

6 Walker e Leitner (2011), em estudo em diferentes localidades dos Estados Unidos, mostram como algumas cidades aprovaram resoluções que criaram multas a empresas ou locatários que empregassem ou alugassem para indivíduos que não dispusessem de provas de residência legal. Outras cidades alteraram os códigos de habitação para impedir que não cidadãos pudessem residir em unidades habitacionais populares. Outras, por fim, estabeleceram restrições à contratação de imigrantes para empregos diários no mercado formal (Walker, Leitner, 2011).

7 Nyers usa a expressão migrantes sem status (non-status migrant) para abarcar todos os tipos de migrantes que não possuem o status legal que permite a residência permanente no país de acolhida - no caso do texto, o Canadá. No entanto, como o autor pontua, as pessoas podem se tornar "sem status" por diferentes razões. Por exemplo, caso sua solicitação de refúgio seja rejeitada (Nyers, 2010, p. 131). 
os não documentados, nas cidades são diretamente permeadas pelo controle de fronteiras e pela cidadania, conceitos que parecem distantes da realidade cotidiana da maior parte dos cidadãos. A indefinição sobre a possibilidade de ficar ou da necessidade de partir, as barreiras no acesso a serviços sociais, apoio e principalmente a direitos; as restrições ao trabalho são algumas das muitas instâncias onde o status legal migratório se expressa não como mera formalidade jurídica, mas como elemento central de marginalização e exclusão.

\section{2. $O$ direito à cidade e a transformação da vida urbana}

Se as cidades abrigam práticas que segregam e excluem indivíduos da participação e pertencimento plenos na comunidade, abrigam ao mesmo tempo possibilidades disruptivas que apontam para a construção de uma vida urbana mais aberta e inclusiva. Essa é a ideia central do que Lefebvre denomina de Direito à Cidade.

O conceito foi originalmente apresentado por Henri Lefebvre em seu livro Le Droit à Ville, de 1968, no qual reflete sobre como os indivíduos se apropriam, participam e transformam os espaços nos quais estão inseridos à despeito dos constrangimentos impostos pelas relações capitalistas dominantes nas cidades, as quais vinculam o pertencimento e o exercício dos direitos ao status socioeconômico individual. O conceito lefebvriano possui, portanto, um caráter utópico e transformador: é um chamado à revolução urbana, através da qual serão reescritas as relações entre os indivíduos e a cidade.

Marcuse (2009) critica o termo "direito", na medida em que o conceito não é um direito no sentido de uma reivindicação legal exigível através do sistema judicial - o que, para Lefebvre, o aproximaria de um projeto burguês liberal - mas um direito que se concretiza nas ações diárias para além das estruturas dominantes. Em suma, como define Mohan (2015), o direito à cidade vai além da garantia de acesso às instalações públicas, aos espaços públicos e aos recursos comuns de propriedade que atualmente constituem a cidade, mas implica em um projeto político para abrir novos espaços públicos e políticos a todos, não importando seu poder econômico ou status jurídico. Aspira à "vida urbana, à centralidade renovada, aos locais de encontro e de trocas, aos ritmos de vida e empregos do tempo que permitem o uso pleno e inteiro desses momentos e locais" (Lefebvre, 1991, p. 139). O direito à cidade é, portanto, "como um grito e uma demanda e (...) só pode ser formulado como um direito transformado e renovado à vida urbana" (Lefebvre, 1996 apud Purcell, 2002, p. 102).

A despeito dos múltiplos significados que o conceito adquiriu ao longo dos anos, com sua incorporação a trabalhos diversos, dois elementos principais - a apropriação e participação - são centrais à sua compreensão. A apropriação engloba o uso completo e integral do espaço por seus habitantes 
e a capacidade de ressignificá-lo em suas rotinas diárias, superando as divisões e os constrangimentos existentes. Inclui, portanto, o direito dos habitantes de acessarem, ocuparem e usarem fisicamente o espaço urbano, mas não somente. Não se trata apenas de ocupar espaços urbanos já produzidos, mas também o direito de produzir o espaço urbano de acordo com as necessidades daqueles que dele se apropriam. O direito à participação envolve a capacidade dos habitantes de controlarem os mecanismos de gestão do espaço urbano. Aponta, assim, tanto para a participação dos excluídos e oprimidos na produção das políticas urbanas quanto o estabelecimento de formas de autogestão, onde se organizam para desafiar as exclusões do poder público ou suprir as lacunas e ausências deste.

Ao colocar a apropriação e a participação no centro de sua efetivação, o direito à cidade reafirma o direito dos habitantes como um todo, de forma indistinta, de produzir, moldar e usar o espaço de acordo com suas necessidades, vontades e desejos. Rompe, assim, as restrições impostas nos modelos democrático-liberais que restringem o usufruto de direitos somente a cidadãos, ampliando as possibilidades do exercício de cidadania para todos aqueles que habitam a cidade, ou, como define, a todos os citadins ${ }^{8}$. Nas palavras de Purcell (2002, p. 103), o direito à cidade "rejeita a noção vestfaliana de que todas as lealdades políticas devem ser subordinadas hierarquicamente à condição de membro da nação. Propõe uma identidade política (citadins) que seja independente e anterior à nacionalidade em relação às decisões que produzem o espaço urbano".

Nos últimos anos, seguindo a trilha aberta por Lefebvre e o direito à cidade, diferentes estudiosos passaram a entender a cidade como um espaço significativo no qual o modelo estadocêntrico de cidadania é redefinido e adquire significados múltiplos (Isin, 2002; Purcell, 2002; Staeheli, 2013; Secor, 2004). A cidadania aqui se afasta da noção de mero status formal concedido aos nacionais de um país e se torna prática e produto da luta política. Como resume Ridgley (2008, p. 55), "ao desafiar leis, práticas e instituições existentes, afirmando novas formas de direitos e critérios de filiação, os habitantes do espaço urbano não apenas mudam as relações sociais existentes, mas muitas vezes reconstituem a substância e o significado da cidadania".

Essa concepção dialética da experiência urbana é sintetizada na distinção que Lefebvre propõe entre dominação e apropriação e, consequentemente, entre espaços dominados e espaços apropriados (Lefebvre, 1991; 1999). A compreensão dessa ambivalência permite avançar uma leitura mais nuançada

8 Lefebvre (1991) propõe a diferenciação entre citadins (todos os habitantes da cidade) e citoyens (aqueles a quem o Estado reconhece a cidadania política) e esclarece que o direito à cidade é de todos os seus habitantes, independentemente de seu reconhecimento legal enquanto cidadãos. 
do processo de inserção de refugiados no meio urbano: leitura que reconhece que as cidades ao mesmo tempo em que ressoam e aprofundam o regime hegemônico de cidadania estadocêntrica, também abrigam processos que o desafiam (Holston, 2007, 2009; Isin, 2000, 2002).

Isso não é simplesmente um fenômeno recente. Ao longo da história, as cidades têm sido espaços políticos onde vários grupos excluídos e marginalizados da cidadania moderna têm avançado demandas por reconhecimento através da mobilização dos recursos urbanos. Como resume Isin (2000, p.1), nelas as mulheres têm lutado para expandir seus direitos de cidadania e direitos sociais como acesso a salários iguais e direito à uma cidade segura; gays para reivindicar direitos que já são extensivos a casais heterossexuais; imigrantes por naturalização e direitos políticos; e vários outros grupos para se tornarem cidadãos plenamente funcionais.

As cidades, portanto, viabilizam a emergência de novas subjetividades políticas através das apropriações, atos ordinários, encontros e solidariedades que se processam em seus espaços e que redefinem as concepções estadocêntricas de pertencimento e direitos. Neste sentido, "tornam-se o local e a substância não apenas das incertezas da cidadania moderna, mas também de suas formas emergentes" (Holston, 2007, p. 23). As práticas não autorizadas/não previstas revelam que a cidadania, apesar de se tornar um meio cada vez mais eficaz de controlar populações em um ambiente globalizado, também traz consigo possibilidades alternativas (e disruptivas) que redefinem as compreensões cristalizadas sobre quem é um cidadão pleno e sobre quais direitos lhes são devidos. Desafiam, assim, sua definição e codificação institucional e revelam sua contingência - longe de ser fixa e imutável, é constantemente contestável e controvertida.

Na seção a seguir, trataremos de iniciativas materializadas em diferentes cidades ao redor do mundo que visam criar um ambiente de hospitalidade aos imigrantes em geral. Mais do que se contrapor à criminalização dessa população, as cidades-santuário se constituem como instâncias de resistência e contestação à ordem policial. Nesse sentido não devem ser lidas apenas como locais de proteção, mas da construção de ideais alternativos de cidadania que garanta a todos, incluindo os não cidadãos, o direito a usufruir de direitos fundamentais e a produzir o espaço urbano em que habitam.

\section{Cidades-santuário e o direito a pertencer}

O crescente processo de criminalização da migração não se dá sem resistências. Diante de políticas nacionais cada vez mais restritivas e excludentes, (re)produzidas na escala urbana, algumas cidades tem respondido oferecendo proteção a refugiados e imigrantes com status irregular. As chamadas "cidades- 
santuário" revelam possibilidades de uma relação potencialmente mais progressista entre cidades e imigrantes do que as observadas até agora.

As primeiras políticas municipais de santuário foram introduzidas na década de 1980, em São Francisco, em um momento onde os discursos públicos denunciavam uma suposta invasão dos Estados Unidos por estrangeiros ilegais e alimentavam sentimentos nativistas ${ }^{9}$. O clima de hostilidade se traduziu em novas políticas de controle direcionadas a latinos nos Estados Unidos que resultaram frequentemente em violações dos seus direitos. Em resposta, São Francisco aprovou dois regulamentos em 1985 e 1989 que proibiram o uso de fundos e recursos locais para colaboração com políticas federais de policiamento migratório, incluindo uma proibição explícita de solicitar, registrar ou divulgar informações sobre o status legal de um indivíduo. O objetivo era acabar com a discriminação contra refugiados salvadorenhos e guatemaltecos pela própria administração local (Ridgley, 2008, p. 29).

Na mesma época, dois estados (Nova York e México) e mais de 20 cidades adotaram resoluções semelhantes, onde declaravam-se santuários para refugiados da América Central. Interessante notar que ao elaborar tais resoluções municipais, os apoiadores recuperaram a tradição histórica das cidades como locais de acolhimento e proteção, fazendo referências às narrativas bíblicas sobre as cidades de refúgio (Ridgley, 2008). Como nos fala Ryan (1987), após a escravidão, os hebreus estabeleceram "cidades de refúgio" que poderiam ser acessadas por uma pessoa que "acidental e involuntariamente" matou outra e estava sendo perseguida pelos parentes da pessoa. Em Atenas, os santuários forneciam proteção para aqueles em busca de refúgio. A palavra asylon expressa a ideia de "inviolabilidade", um local do qual nada pode ser tirado nem ninguém pode ser violado. Dessa forma, tudo que aqueles em busca de proteção deveriam fazer era adentrar esses espaços sagrados e estariam a salvo, não podendo ser removidos à força (Marfleet, 2007; Pedley, 2005; Weis, 1966).

Na Idade Moderna, os grupos que hoje se encaixariam na definição atual de refugiados eram basicamente de origem urbana e encontraram santuário especialmente no meio urbano (Marfleet, 2007). Durante o século XIX, ativistas radicais ou líderes nacionalistas envolvidos em movimentos na Itália, Hungria, Áustria, Polônia e Alemanha procuraram refúgio nas cidades de países vizinhos, onde podiam manter comunicação com outros exilados e com os movimentos em seus países de origem (Marfleet, 2007).

\footnotetext{
9 Nos países desenvolvidos, os anos 80 marcaram o fim da era de acolhimento vigente desde o fim da $2^{\underline{a}}$ Guerra Mundial, quando a economia aquecida garantiu fronteiras abertas à mão-deobra migrante, recrutada na periferia da Europa, nos territórios coloniais e nas regiões mais pobres do globo através dos programas de guest-workers. Diferentes governos patrocinaram programas de incentivo ao retorno dos estrangeiros outrora bem-vindos e adotaram políticas restritivas sob o argumento do combate aos imigrantes ilegais. Nos Estados Unidos, a figura do estrangeiro ilegal se associou a imigrantes mexicanos e da América Central. Para saber mais: Bravo, 2019; Castles, 1986.
} 
Nos Estados Unidos, atualmente, mais de 45 cidades norte-americanas têm políticas em vigor que vão na contramão das leis federais de imigração e visam criar um ambiente de acolhimento a imigrantes, independentemente de seu status (Marfleet, 2007). Parte dessas resoluções e legislações municipais visa facilitar o acesso aos serviços municipais. Algumas localidades reconhecem documentos do país de origem (por exemplo, carteiras de motorista ou certidões consulares) como documentos oficiais de identificação; outras emitem seus próprios cartões de identificação, que são projetados para serem usados por todas as pessoas residentes na cidade. Outra parte das políticas proíbe o uso de recursos municipais para fazer cumprir as leis federais relacionadas à imigração estratégia; enquanto outras seguem a estratégia "Não Pergunte, Não Fale", proibindo os funcionários da cidade de coletar e disseminar informações sobre o status de uma pessoa (ver, por exemplo, Bagelman, 2013; Darling 2010; Darling, Squire, 2013; Squire, 2011).

O movimento "Não Pergunte, Não Fale"10 inspirou manifestações semelhantes em Toronto, no ano de 2004, quando um grupo de ativistas tomou as ruas para reivindicar que os prestadores de serviços municipais não solicitassem aos clientes informações sobre seu status e que, caso obtivessem informações, não compartilhassem com as autoridades federais. Dessa maneira, as barreiras ao acesso aos serviços públicos poderiam ser reduzidas para os residentes ilegalizados (Bauder, 2015, p. 260). Nove anos depois, após forte campanha liderada por uma série de organizações comunitárias e grupos de defesa dos direitos dos migrantes, Toronto se tornou oficialmente uma cidade santuário, adotando uma moção que fortaleceu seu compromisso em garantir que todos os moradores da cidade pudessem viver sem medo de abuso, detenção ou deportação; que pudessem acessar com segurança serviços à despeito do status migratório, e que pudessem participar da vida cívica urbana (Bauder, 2015).

Na Europa, na esteira da chamada crise dos refugiados, em 2015, dezenas de cidades e comunidades tomaram medidas para combater a hostilidade dos governos nacionais quando se trata de receber imigrantes. O prefeito de Atenas lançou a iniciativa Cidades Solidárias, que visa estimular a adesão de diferentes cidades da União Europeia para gerenciar a situação dos refugiados em nível local, respeitando os princípios de responsabilidade e solidariedade no campo da recepção e integração ${ }^{11}$. Na Bélgica, após o lançamento da

${ }^{10}$ Don't ask, don't tell, no original.

11 O programa Cities está estruturado em quatro pilares: 1) intercâmbio de informações e conhecimentos sobre a situação dos refugiados nas cidades; 2) advogando por um melhor envolvimento e financiamento direto para as cidades na recepção e integração de refugiados; 3) assistência e capacidade técnica e financeira de cidade para cidade edifício; 4) promessas das cidades europeias de receber requerentes de asilo recolocados. 
campanha Communes hospitalières (municípios hospitaleiros), sessenta e dois municípios de língua francesa se declararam hospitaleiros para os imigrantes comprometendo-se a aumentar a conscientização de seus moradores sobre as questões de migração e garantir que uma política de acolhimento de imigrantes genuinamente acolhedora seja implementada em seu território.

Em outros casos, as atividades de solidariedade lideradas pelos cidadãos vieram antes das políticas. A iniciativa We are a Welcoming Europe: Let us Help! reivindica que a Comissão Europeia dê suporte a grupos locais envolvidos no processo de acolhimento e integração de imigrantes e refugiados ${ }^{12}$. Já a "Cities of Refuge" tem como objetivo melhorar os processos locais de integração dos refugiados a partir das leis internacionais de Direitos Humanos. Há também iniciativas mais espontâneas e menos organizadas que são comumente substituídas por serviços públicos e organizações sociais reconhecidas, as quais "muitas vezes possuem uma definição muito mais restritiva de quem deveria ser acolhido e em que bases" (Mayer, 2018)

Além disso, como ressalta Garcés-Mascarenãs (2019), desde 2015, as cidades europeias tem se aproximado das cidades norte-americanas no que diz respeito ao enfrentamento aos governos nacionais na arena política.

Por exemplo, o Conselho da Cidade de Barcelona, liderado pela prefeita Ada Colau, condenou a União Europeia e seus estados membros, dizendo que suas políticas a deixavam "envergonhada" e pedindo repetidamente que as cidades desempenhassem um papel maior nas políticas de acolhimento de refugiados. Ao longo de 2018 e 2019, cidades italianas como Palermo e Nápoles denunciaram a política do ministro do Interior italiano, Matteo Salvini, contra ONGs de resgate marítimo, enquanto outras como Barcelona e Valência pediram ao governo espanhol do PSOE para abrir os portos. Nos últimos anos, certas cidades europeias tornaram-se sujeitos políticos em questões de controle de fronteiras e política de migração, bem como na arena internacional.

Se todas essas iniciativas têm algo em comum, é um certo questionamento ou, em alguns casos, um desafio ao estado atual da governança da migração. Se todas essas iniciativas têm algo em comum, é um certo questionamento ou, em alguns casos, um desafio aos efeitos repressivos dos controles de imigração. As cidades que se proclamam cidades-santuário fazem um contraponto ao monopólio estatal e ao modelo de pertencimento em bases nacionais recuperando a distinção elementar entre citoyens e citadins. Sua possibilidade de existir e pertencer à cidade não se dá com base na posse da cidadania, mas pelo fato de habitarem e residirem no espaço urbano.

\footnotetext{
12 Graças à campanha, em 5 de julho de 2018, o Parlamento Europeu adotou uma resolução sobre diretrizes para os Estados-Membros impedirem a criminalização da assistência humanitária. Além disso, a Comissão Europeia concordou publicamente em coletar e fornecer casos para um Observatório Europeu. Para saber mais: <https://www.migpolgroup.com/index.php/portfolioitem/welcoming-europe/; https://ec.europa.eu/commission/presscorner/detail/en/IP_18_746>.
} 
As discussões sobre as cidades como um santuário em potencial são úteis, portanto, para destacar possibilidades contingentes que pavimentam o caminho para maiores perspectivas de inclusão dos imigrantes à vida urbana. No entanto, elas também apontam para os limites de tais movimentos. Bagelman (2013) e Squire (2012) realçam como os gestos de hospitalidade reproduzem uma lógica pastoral na qual os imigrantes são postos como objetos de caridade a serem assistidos pelos cidadãos locais. Despolitiza-se o migrante, anulando sua agência. Sua existência passa a depender da generosidade dos outros (Malkki, 1996).

Chauvin e Garcés-Mascarenãs (2012), por sua vez, mostram como estes gestos refletem a racionalidade estatal que estabelece distinções hierárquicas e mecanismos de governança para administrar os imigrantes. Vistas por esse viés, as legislações e resoluções municipais funcionaram não como caminho para construção de uma cidadania urbana, mas como forma de regular a presença de imigrantes não documentados e seu acesso aos serviços municipais - atenuando as preocupações com a manutenção da ordem pública (Darling, 2016).

A despeito das críticas, não é possível se obliterar o potencial disruptivo das que as práticas engendradas pelas cidades-santuário. Mesmo que (re) produtoras de uma lógica regulatória e/ou pastoral, representam uma ruptura nos impedimentos e interdições colocados aos imigrantes indocumentados pela ordem hegemônica. Para Lefebvre, as ações transformadoras não residem nos grandes atos revolucionários apenas, mas nascem nas fissuras e dobras dessa ordem. Nesse sentido, as políticas de cidade-santuário, ao permitir que todos os habitantes urbanos participem "da representação cotidiana da cidade através de suas rotinas, práticas e ritmos" (Squire, Darling, 2013, p. 201) permite que os imigrantes assumam um papel ativo na produção do espaço urbano, conforme previsto por Lefebvre. As novas relações, interações e modos de vida habilitados por essas práticas trazem em si a capacidade de mudar profundamente as ideias em torno da comunidade e da pertença, trazendo a possibilidade real de que categorias como Estado-nação, cidadão ou migrante se tornem obsoletas.

\section{Notas Finais}

As cidades têm constituído espaços fundamentais para aplicação e aprofundamento das leis nacionais que situam a imigração como uma questão de lei e ordem. Nos espaços da cidade, as ideias prevalentes sobre pertencimento, soberania e direitos, implícitas nas políticas e práticas estatais, se materializam e atravessam a vida cotidiana de imigrantes.

O controle migratório (e a consequente produção da ilegalidade) se espraia por diferentes atores locais e espaços do dia-a-dia. Detenções 
arbitrárias, batidas policiais nos espaços de lazer e de trabalho, paradas frequentes para verificação de documentação, entre outras práticas locais de controle imigratório, ameaçam seus direitos mais básicos e revelam como estes indivíduos são relegados a espaços de exceção - nos quais surgem como vidas indignas de usufruírem das mesmas condições que os nativos.

Como nos lembra Lefebvre, no entanto, as cidades não são apenas espaços de policiamento, mas também locais estratégicos importantes para a política ativista transformadora. Através de apropriações não-programadas, alianças entre cidadãos e não cidadãos e atos de solidariedade, os projetos de demarcação de fronteiras, refletidos e aprofundados em nível urbano, são desafiados. A atenção a essas práticas permite se afastar do viés securitário e nacional - que dominam as discussões contemporâneas da política de imigração - e instiga que se repense as noções cristalizadas de cidadania e comunidade política.

O movimento das cidades-santuário traz em si o potencial de ampliar os limites do político - moldado por concepções estadocêntricas de pertencimento que negam aos não cidadãos o direito de participar da vida social e política. Ao se contrapor a essa ordem hegemônica, promovem uma mudança da escala nacional para a urbana, aproximando-se da noção Lefebvriana de direito à cidade: enquanto as políticas e leis nacionais promovem a exclusão de imigrantes, as políticas e a legislação vigentes nas cidades-santuário os incluem com base em sua condição de habitante do espaço urbano e não em sua filiação nacional. Ao desafiar as leis nacionais, essas políticas e práticas urbanas reforçam o olhar Lefebvriano sobre as cidades como "um dos principais locais onde novas normas e novas identidades são feitas" (Sassen, 2013, p.69)

Não se trata, porém, de recair na romantização dessas práticas. Como vimos, nem todas possuem um caráter revolucionário, na concepção tradicional do termo, que aponta pra a reforma profunda das estruturas geradoras de desigualdade e exclusão. Longe de transformadoras, assumem um caráter instrumental onde reivindicam a inserção nas estruturas cristalizadas de direitos. No entanto, o viés conservador de muitas dessas manifestações não retira seu caráter disruptivo e, consequentemente, as possibilidades que dele podem emergir.

A teoria de Lefebvre e sua ênfase sobre a práxis não aponta em direção a um projeto finalizado, mas de uma possibilidade em marcha, existente enquanto virtualidade, situada no plano do devir, do vir-a-ser, que abrirá novas possibilidades de apropriação e participação na cidade para seus habitantes. Assim, as políticas de santuário, se não reivindicam a mudança profunda e imediata da ordem, traz à tona possibilidades até então invisibilizadas. Instiga, dessa forma, que se repense as noções cristalizadas de cidadania e comunidade 
política, colocando no plano do devir a utopia de um mundo onde ninguém seja ilegal.

\section{Referências bibliográficas}

BAGELMAN, Jen. Sanctuary: A politics of ease? Alternatives: Global, Local, Political, v. 38, n. 1 p. 49-62, 2013.

BALIBAR, Étienne. The borders of Europe. In: CHEAN, Pheng; ROBBINS, Bruce. Cosmopolitics. Minneapolis: University of Minnesota Press, 1998.

BAUDER, Harald. Possibilities of urban belonging. Antipode, v. 48, n. 2, p. 252-271, 2016.

BOSWELL, Christina. Burden-Sharing in the European Union: Lessons from the German and UK Experience. Journal of Refugee Studies, v. 16, n. 3, p. 316-335, 2003.

BRAVO, André Luiz Morais Zuzarte. Entre a "crise do refúgio" e a "crise das cidades": uma análise sobre a inserção de refugiados no meio urbano (Tese de doutorado). Pontifícia Universidade Católica do Rio de Janeiro, Instituto de Relações Internacionais, 2019.

BROWN, Wendy. Walled states, waning sovereigns. London: Zone Books, 2010.

CASTLES, Stephen. The Guest-Worker in Western Europe - An Obituary. International Migration Review, v. 20, n. 4, Special Issue: Temporary Worker Programs: Mechanisms, Conditions, Consequences, p. 761-778, 1986.

CHAUVIN, Sébastien; GARCÉS-MASCAREÑAS, Blanca. Beyond informal citizenship: The new moral economy of migrant illegality. International Political Sociology, v. 6, n. 1, p. 241-259, 2012.

CIERCO, Teresa; SILVA, Jorge Tavares da. The European Union and the Member States: two different perceptions of border. Rev. bras. polit. int., Brasília, v. 59, n. 1, 2016.

DARLING, Jonathan; SQUIRE, Vicki. Everyday enactments of sanctuary: The UK City of Sanctuary movement. In: LIPPERT, Randy K.; REHAAG, Sean (eds.). Sanctuary Practices in International Perspectives: Migration, Citizenship and Social Movements. Londres: Routledge, 2013, p.191-204.

DARLING, Jonathan. A city of sanctuary: The relational re-imagining of Sheffield's asylum politics. Transactions of the Institute of British Geographers, v. 35, n. 1, p. 125-140, 2010.

DARLING, Jonathan. Forced migration and the city: Irregularity, informality, and the politics of presence. Progress in Human Geography, v. 41, n. 2, p. 1-21, 2016.

FASSIN, Didier. Policing borders, producing boundaries. The governmentality of Immigration in Dark Times. Annual Review of Anthropology, v. 40, n. 1, p. 213 226, 2011.

GARCÉS-MASCAREÑAS, Blanca. Sanctuary cities: a global perspective. Barcelona Centre for International Affairs, 2019. Disponível em: < https://www.cidob. org/en/articulos/anuario_internacional_cidob/2019/sanctuary_cities_a_global_ perspective $>$. Acesso em: 10.01.2020. 
HARVEY, David. Cidades rebeldes: do direito à cidade à revolução urbana. São Paulo: Martins Fontes, 2014.

HASSNER, Ron; WITTENBERG, Jason. Barriers to Entry: Who Builds Fortified Boundaries and Why? International Security, v. 40, n. 1, 2015.

HYNES, Patricia. Contemporary Compulsory Dispersal and the Absence of Space for the Restoration of Trust. Journal of Refugee Studies, v. 22, n. 1, p. 97-121, 2009.

HOLSTON, James. Insurgent Citizenship in an Era of Global Urban Peripheries. City \& Society, v. 21, n. 2, p. 245-267, 2009.

HOLSTON, James. Citizenship in disjunctive democracies. In: TUCHIN, Joseph S.; RUTHENBURG, Meg. Citizenship in Latin America. Boulder: Lynne Rienner, p. 75-94, 2007

ISIN, Engin. City, Democracy and Citizenship: Historical Images, Contemporary Practices. In: ISIN, Engin; TURNER, Bryan S. (eds.). Handbook of Citizenship Studies. London: Sage, 2002.

ISIN, Engin. Democracy, Citizenship and the Clobal City. Innis Centenary Series. London: Routledge, 2000.

ISIN, Engin. The Neurotic Citizen. Citizenship Studies, v. 8, n. 3, p. 217-235, 2004.

LEFEBVRE, Henri. A Revolução Urbana. Belo Horizonte: Ed. UFMG, 1999.

LEFEBVRE, Henri. O direito à cidade. São Paulo: Centauro, 2001.

LEFEBVRE, Henri. The production of space. Oxford: Blackwell publishing, 1991.

LEFEBVRE, Henri. Writing on Cities. London: Blackwell, 1996.

MAGNUSSON, Warren. Politics of Urbanism: Seeing like a City. London: Routledge, 2011.

MALKKI, Liisa. Refugees and exile: from "refugee studies" to the national order of things. Annual Review of Anthropology, v. 24, n. 1, p. 495-523, 1995.

MALKKI, Liisa. Speechless Emissaries: Refugees, Humanitarianism, and dehistoricization. Annual Review of Anthropology, v. 11, n. 23, p.495-523, 1996.

MARCUSE, Peter. From critical urban theory to the right to the city. City, v. 13, n. 1, p. 185-197, 2009.

MARFLEET, Philip. 'Forgotten', 'hidden': Predicaments of the urban refugee. Refuge, v. 24, n. 1, p. 36-45, 2007.

MARGIT, Fauser. The emergence of urban border spaces in Europe. Journal of Borderlands Studies, v. 18, n. 1, p. 1-18, 2017.

MAYER, Margit. Cities as sites of refuge and resistance. European Urban and Regional Studies, v. 25, n. 3, p. 232-249, 2018.

MOHAN, Sudha. As Políticas de Espaço Urbano no Contexto do Direito à Cidade na Megacidade de Mumbai, Índia. In: ESTEVES, Paulo; VELLOSO, Sérgio (eds.). Direito à cidade para um mundo justo e seguro: o caso dos BRICS. Rio de Janeiro: BPC, 2015.

NYERS, Peter. No One is Illegal Between City and Nation. Studies in Social Justice v. 4, n. 2, p.127-143, 2010 
OVAL OFFICE. President Donald J. Trump's Address to the Nation on the Crisis at the Border. Disponível em: <https://www.whitehouse.gov/briefings-statements/ president-donald-j-trumps-address-nation-crisis-border/> . Acesso em: 10.01.2020 PEDLEY, John. Sanctuaries and the Sacred in the Ancient Greek World. Cambridge: Cambridge University Press, 2005.

PURCELL, Mark. Excavating Lefebvre: The right to the city and its urban politics of the inhabitant. GeoJournal, v. 58, p. 99-108, 2002.

RAMO, Joshua. The Seventh Sense: Power, Fortune and Survival in the Age of Networks. New York: Little, Brown and Company, 2016.

RIDGLEY, Jennifer. Cities of Refuge: Immigration Enforcement, Police, and the Insurgent Genealogies of Citizenship in us Sanctuary Cities. Urban Geography, v. 29, n. 1, p. 53-77, 2008.

RYAN, William C. The Historical Case for the Right of Sanctuary. Journal of Church and State, v. 29, n. 2, p. 209-232, 1987.

SASSEN, Saskia. When the centre no longer holds: Cities as frontier zones. Cities, v. 34, n. 1, p. 67-70, 2013.

SECOR, Anna. "There Is an Istanbul That Belongs to Me": Citizenship, Space, and Identity in the City. Annals of the association of American Geographers, v. 94, n. 2, p. 352-368, 2004.

SQUIRE, Vicki. From community cohesion to mobile solidarities: The City of Sanctuary network and the Strangers into Citizens campaign. Political Studies, v. 59, n. 1, p. 290-307, 2011.

SQUIRE, Vicki; BAGELMAN, Jennifer. Taking not Waiting: Space, temporality and politics in the City of Sanctuary movement. In: NYERS, Peter; RYGIEL, Kim (eds.). Citizenship, Migrant Activism and the Politics of Movement. Abingdon: Routledge, 2012.

SQUIRE, Vicki; DARLING, Jonathan. The 'minor' politics of rightful presence: Justice and relationality in the City of Sanctuary. International Political Sociology, v. 7, n. 1 p. 59-74, 2013.

STAEHELI, Lynn. Cities and Citizenship. Urban geography, v. 24, n. 2, p. 97-102, 2013.

STONE, Jon. The EU has built 1,000km of border walls since fall of Berlin Wall. The Independent. Londres. nov. 2018. Disponível em: <https://www.independent. co.uk/news/world/europe/eu-border-wall-berlin-migration-human-rightsimmigration-borders-a8624706.html>. Acesso em: 9 nov. 2018.

VARSANYI, Monica W. Immigration Policing Through the Backdoor: City Ordinances, the "right to the City," and the Exclusion of Undocumented Day Laborers. Urban Geography, v. 29, n. 1, p. 29-52, 2008.

WALKER, Kyle E.; LEITNER, Helga. The Variegated Landscape of Local Immigration Policies in the United States. Urban Geography, v. 32, n. 2, p. 156-178, 2011.

WEIS, Paul. Territorial Asylum. Indian Journal of International Law, n. 6, p. 173-94, 1966. 